\title{
Stamp watching and bird collecting
}

from Robert M. May and Judith May

AESTHETICALLY and philatelically the recent issue of US bird-and-flower stamps is remarkable; each sheet has $\mathbf{5 0}$ different 20 cent stamps, depicting the 'state bird' and 'state flower' of each of the 50 states. Scientists may find them additionally interesting for the way they exemplify the peculiarity of our engagement with the order Aves.

Knowing nothing about how the state birds were originally chosen, and given that there are 700 or so species to choose from, one can generate all manner of hypotheses about the diversity of bird species to be found on this set of stamps. The 'null hypothesis' would be that the states chose their birds independently and randomly, in which case we would expect only one or two pairs of states to have chosen the same bird species, and the remaining 48 or 46 states each to have made a unique choice. Of course, this null hypothesis is obviously too simple, as it overlooks biological complications in the relative abundance and geographical distribution of birds, historical and cultural factors in the founding of states, and the particular aesthetic attractions of the favoured species. The stamps in fact show the state birds to be a much less diverse assembly than would be expected on any biological grounds: 7 cardinals (for states from the east coast to Kentucky and Indiana); 6 western meadowlarks (mainly in the north-west); 6
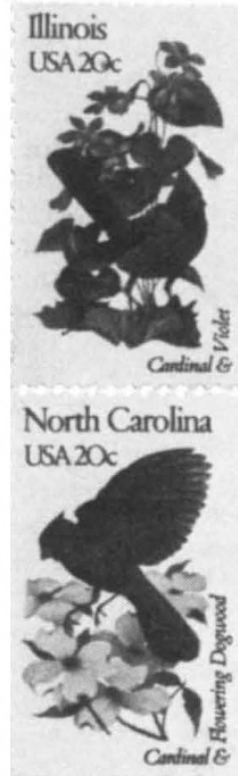
mockingbirds (from southern states); 3 robins; 2 mountain bluebirds; 2 eastern bluebirds; 2 American goldfinches; 2 chickadees; and only 21 singletons.

Over the years, scientists too have shown that they are not immune to avian charms (though the sheer conspicuousness of birds, in comparison with most other vertebrates, undoubtedly accounts for some of this popularity). From Gilbert White's time onwards, a grossly disproportionate number of evolutionary and

Robert M. May is Class of 1877 Professor of Zoology at Princeton University, New Jersey 08544, and Judith May is an Editor at Princeton University Press.
From their point of view, North America is a richer place than Britain; around 660 species of birds breed in North America (excluding Greenland, Bermuda and Baja California) and around 710 species are regularly seen, whereas only around 190 species of birds breed in Britain and only around 240 species are regularly seen. This difference in the number of breeding bird species is almost exactly what would be expected from the MacArthur-Wilson species-area relation, $S \sim A^{z}$, with $z \sim 1 / 4$; the ratio of the area of North America to that of Britain is roughly 80 , whence we would expect roughly a ratio of 3 in the number of species. The agreement is surprising, and must surely be largely coincidental, because the underlying premises from which the species area relation is deduced pertain more to archipelagoes of islands than to large continental masses.

The list of species ever seen in North America totals around 820 . In Britain the list numbers around 470 , many of which are rare sightings of birds that are lost and do not want to be there. From these numbers it can incidentally be seen that membership in the 600 club' (a life list of 600 North American birds) is a substantial but not unreasonable goal. More arcane are competitions centering on the greatest number of bird species sighted in North America in one year, or simply the greatest number of species seen in any one

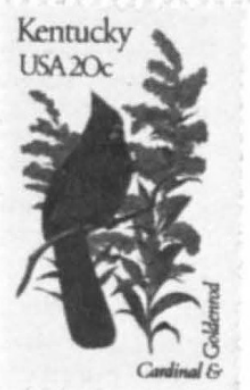
day, or even by turning through $360^{\circ}$ on one spot. The record for North American bird species seen in one calendar year was until recently held by Scott Robinson, now a Princeton University graduate student, at 657 . In 1979, a businessman named Vardaman spent a small fortune in pursuit of the ambition of sighting 700 species in one year. Travelling extensively and advertising widely for people to lead him to rare birds, Vardaman pushed the total number of species he had seen above 690 in the last weeks of December. The magic 700 was to elude him, however. At the year's end Vardaman's record stood at 699. God too is clearly an amateur bird lister. been overcome by the surprising (and perhaps more widely applicable) finding that small positively charged, DNA-free liposomes greatly stimulate polyethylene glycol-assisted transfection of protoplasts (J. Makins, et al., John Innes Institute).

Cloning systems are especially useful when allied with in vivo genetics. This has been made easier in Streptomyces by several recent developments. For example, the multicopy $8.9 \mathrm{~kb}$ plasmid $\mathrm{pIJ} 101$ is a very efficient sex factor which can be transferred into nearly all streptomycetes (D. Hopwood). Other generalized tech- niques for achieving efficient chromosomal recombination in Streptomyces include protoplast fusion ${ }^{2}$ and liposomemediated transformation ${ }^{3}$. Perhaps less widely applicable is a system for $\mathrm{Ca}^{2+}$. promoted transformation of competent $S$. griseus cultures by plasmid DNA (Z. Zhuang et al., Institute of Microbiology, Beijing) and the discovery of a (probably narrow host range) temperate phage of $S$. fradiae which exists as a plasmid prophage and is capable of generalized transduction (S. T. Chung, The Upjohn Company, Kalamazoo).
Evidently the immediate future will see the detailed analysis of primary and secondary metabolism and differentiation in Streptomyces, together with a widening of our vision of prokaryotic genome structure. Some of the new techniques are sure to influence industrial programmes and may lead to the use of streptomycetes as hosts for foreign DNA expression.

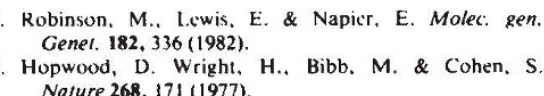

